\title{
Antitumor effect and mechanism of action of a tumor-targeting recombinant human tumor necrosis factor- $\alpha$ fusion protein mediated by urokinase
}

\author{
YOU-CHAO DAI ${ }^{1}$, SI-MIN YANG ${ }^{1}$, XIN WANG $^{1}$, YONG-JUN ZHOU ${ }^{2}$, GAN HOU $^{2}$ and DI-NAN HUANG ${ }^{2}$ \\ ${ }^{1}$ Institute of Medical Inspection; ${ }^{2}$ Department of Clinical Biochemistry, Guangdong Medical College, \\ Zhanjiang, Guangdong 523808, P.R. China
}

Received March 15, 2014; Accepted December 12, 2014

DOI: $10.3892 / \mathrm{mmr} .2015 .3313$

\begin{abstract}
The aim of this study was to investigate the effect of the tumor-targeting recombinant human tumor necrosis factor (rhTNF)- $\alpha$ fusion protein mediated by urokinase on S180 tumor-bearing mice, as well as to explore its mechanisms of action. Furthermore, the study aimed to observe the effect of the protein on liver and kidney function. rhTNF- $\alpha$ fusion protein prokaryotic expression vectors were constructed using genetic engineering techniques, and were introduced into Escherichia coli. Expression of the fusion protein was induced, and it was then separated and purified in order to determine its cytotoxic activity on L929 cells. Kunming mice were randomly divided into four groups after being inoculated with S180 tumor cells. The groups were then injected with saline (control group, group S), or saline with $0.1 \mu \mathrm{g} / \mathrm{ml}$ fusion protein (low dose group, group L), $0.2 \mu \mathrm{g} / \mathrm{ml}$ fusion protein (middle dose group, group M) or $0.3 \mu \mathrm{g} / \mathrm{ml}$ (high dose group, group H). The mice were sacrificed after 12 days and liver [mg/kg; (liver weight/body weight) x 1,000] and kidney $[\mathrm{mg} / \mathrm{kg}$; (kidney weight/body weight) x 1,000] indices, tumor weight, the percentage reduction in mean tumor size, and the levels of alanine transaminase (ALT), albumin (ALB), creatinine (Cr) and blood urea nitrogen (BUN) in each group of mice were determined. In addition, the levels of urokinase-type plasminogen activator (uPA), the expression of bcl-2, bax and vascular endothelial growth factor (VEGF), and the percentage of apoptotic cells were measured with an enzyme-linked immunosorbent assay, streptavidin-biotin complex of immunohistochemistry and terminal deoxynucleotidyl transferase-mediated dUTP
\end{abstract}

Correspondence to: Professor Gan Hou, Department of Clinical Biochemistry, Guangdong Medical College, 2 Wenming Dong Road, Zhanjiang, Guangdong 523808, P.R. China

E-mail: houganhwj@126.com

Key words: urokinase, recombinant tumor necrosis factor- $\alpha$, fusion protein, S180 tumor, antitumor effect, liver function, kidney function, apoptosis nick end labeling, respectively. The fusion protein significantly inhibited the growth of S180 tumor cells in vivo in a dose-dependent manner. With an increase in the dose of fusion protein, ALT, uPA, bcl-2 and VEGF levels decreased, and ALB levels increased. However, liver and kidney indices and bax expression were not significantly altered. Cr and BUN levels did not change significantly in the low and middle dose groups, but did increase in the high dose group. Compared with the control group, the percentage of apoptotic cells in the high-dose group was significantly higher. In conclusion, the fusion protein significantly inhibited S180 tumor growth in a mouse model, possibly by reducing the levels of uPA, bcl-2 and VEGF. There was a mildly toxic effect on the kidneys with the high dose, but a protective effect in the liver.

\section{Introduction}

Human tumor necrosis factor (hTNF)- $\alpha$ is a multifunctional cytokine produced by activated macrophages. TNF- $\alpha$ is known to have potent antitumor properties in vivo and in vitro (1), and thus has potential clinical applications in cancer treatment. However, it is unstable with a short half-life and significant side effects in vivo, which greatly restricts its use in a clinical setting.

Urokinase-type plasminogen activator (uPA) is a serine protease. It is able to activate the conversion of plasminogen to plasmin, which is then involved in triggering the fibrinolysis of a variety of matrix proteins. A number of studies have suggested (2-4) that the over-expression of uPA is important in the evolution of malignant tumors, and that it is closely correlated with tumor cell proliferation, angiogenesis, tumor invasion, metastasis and the inhibition of apoptosis. uPA is highly expressed in tumor tissues, but low or no expression is observed in normal tissues. Furthermore, it displays a high affinity for the specific substrate, plasminogen. Therefore, hTNF- $\alpha$ mediated by uPA may exhibit a decrease in the toxicity compared with wild-type hTNF- $\alpha$ and also solve the problem of tumor targeting, as it is only active when cleaved by tumor-expressing urokinase.

The current study was conducted in order to obtain preliminary data on the effect of a novel hTNF- $\alpha$ fusion protein on tumor suppression, its mechanism of action and its influence on liver and renal function. 


\section{Materials and methods}

Expression vectors, cell lines and animals. Escherichia coli with Rosetta2 was purchased from Novagen (Madison, WI, USA). The S180 mouse cells were provided by the laboratory of Guangdong Medical College (Donguang, China). Kunming mice, (body weight, 28-30 g); 18:18, male:female, were obtained from The Animal Center of Guangdong Medical College. Animals were housed in a temperature-controlled room $\left(24^{\circ} \mathrm{C}\right)$ with a $12 \mathrm{~h} / 12 \mathrm{~h}$ cycle of light and dark and were allowed ad libitum access to food and water throughout the experiment. The study was approved by the ethics committee of the Experimental Animal Center of Guangdong Medical College (Zhanjiang, China).

Primary instruments. Vertical electrophoresis, electrophoresis apparatus and a 450 enzyme-labeled meter were purchased from Bio-Rad (Hercules, CA, USA). An HWI thermostatic water tank was purchased from Beijing Medical Equipment Factory (Beijing, China). An MAIS pathological color image analyzer, a microscope (CX31; Olympus Corp., Tokyo, Japan) and any relevant software (MAIS image-Pro System, version 2000-P2; Jiangsu Software Technology Co., Ltd., Zhejiang, China) were provided by the Department of Pathology, Guangdong Medical College. All other frequently-used apparatus was provided by the Biochemical Laboratory of Guangdong Medical College.

Drugs and reagents. The fusion protein was extracted in concentrations of $0.1,0.2$ and $0.3 \mu \mathrm{g} / \mu \mathrm{l}$. BugBuster Protein Extraction kits were obtained from Novagen. uPA assay kits, terminal deoxynucleotidyl transferase-mediated dUTP nick end labeling (TUNEL) kits, bcl-2 immunohistochemical assay kits, bax immunohistochemical assay kits and vascular endothelial growth factor (VEGF) immunohistochemical kits were all obtained from Shanghai Bogu Biological Technology Co., Ltd. (Shanghai, China). Other reagents were obtained from the Biochemical Laboratory of Guangdong Medical College.

Plasmid construction. The plasmid pET-42a(+)-foldon-uPA-hTNF- $\alpha$ was made by cloning the foldon sequence, the uPA distinguishing sequence and the wild-type hTNF- $\alpha$ sequence [with eight amino acids (aa) deleted in the $\mathrm{N}$ terminal] into a pET-42a(+) vector (Zhejiang Tianhang Biological Technology Co., Ltd., Hangzhou, China). Using two 5 '-end modified PCR (that is adding a synthetic nucleotide sequence to the $5^{\prime}$ end), the foldon sequence, uPA distinguishing sequence and wild-type hTNF- $\alpha$ sequence (with eight aa deleted in the $\mathrm{N}$ terminal) of a total 572bp was cloned into pET-42a between the PshA and Sac restriction enzyme sites and thus the pET-42a (+)-foldon-uPA-hTNF recombinant plasmid was obtained. It carried a GS-foldon sequence (27 aa), a GS-uPA distinguishing sequence ( $7 \mathrm{aa}$ ) and an hTNF- $\alpha$ sequence with 8 aa deleted from the $\mathrm{N}$ terminal. The GS-foldon sequence encodes 29 aa, GYIPEAPRDGQAYVRKDGEWVLLSTFL and each end of the GS has a connecting function to foldon sequence and a uPA distinguishing sequence. The uPA distinguishing sequence was Pro Gly Arg $\downarrow$ Val Ala Lys. $\downarrow$ Represents the cleavage site of uPA.
Expression, extraction, purification and deblocking of the fusion protein. Rosetta2 (DE3; Zhejiang Tianhang Biological Technology Co., Ltd.) with the correct sequence was grown in luria broth (LB) agar containing kanamycin (Kana) and chloramphenicol (Cam) at an appropriate concentration to obtain the monoclone. The monoclone was grown overnight at $37^{\circ} \mathrm{C}$ in $3 \mathrm{ml} \mathrm{LB}$ liquid medium containing $30 \mathrm{mg} / \mathrm{ml} \mathrm{Kana}$ and $34 \mathrm{mg} / \mathrm{ml} \mathrm{Cam}$. The culture was then diluted into 3 litres of medium containing Kana, and grown at $37^{\circ} \mathrm{C}$ until the culture reached an $\mathrm{A}_{600}$ of 0.5 (MCF Nephelometer wi93008; Dongxiyi Technology Co., Ltd., Beijing, China). The culture was diluted to a final concentration of $0.8 \mathrm{mmol} / \mathrm{l}$ by adding IPTG (Dongguan Mag Biotechnology Science Co., Ltd., Dongguan, China) at $20^{\circ} \mathrm{C}$ and agitating at $160 \mathrm{rpm}$ for $24 \mathrm{~h}$. The cells were collected by centrifugation at $3,000 \mathrm{x} \mathrm{g}$ for $15 \mathrm{~min}$ at $4^{\circ} \mathrm{C}$, after the culture had been on ice for $10 \mathrm{~min}$. The collected cells were suspended in phosphate-buffered saline (PBS), then removed by centrifugation at $3,000 \mathrm{x} \mathrm{g}$ for $15 \mathrm{~min}$ at $4^{\circ} \mathrm{C}$. The cells were weighed and treated according to the manufacturer's instructions of the BugBuster GST-Bind Purification kits) in order to extract the soluble protein. The fusion protein was removed from glutathione S-transferase (GST) by Factor Xa (Novagen), and the target protein was obtained from the collected elution. The fusion protein levels were analyzed by separating the proteins with $6 \%$ SDS-PAGE, followed by staining with coomassie brilliant blue. The concentration of fusion protein without the GST tag was detected by bicinchonininc acid and the pick-up rate was calculated: Pick-up rate $=$ fusion protein rate/bacteria rate. The deblocked fusion protein was the product of uPA acting on the uPA dsitinguishing sequence in the rhTNF within a Tris- $\mathrm{HCl}$ buffer of $\mathrm{pH} 7.5$.

Cytotoxic activity of fusion protein on L929 cells by an 3-(4,5-dimethylthiaxol-2-yl)-2-5-diphenyltetrazolium (MTT) assay. Cytotoxic activity was estimated by an MTT assay, as described previously (5). The suspension was adjusted with L929 cells in logarithmic growth to a concentration of $2 \times 10^{5}$ cells $/ \mathrm{ml}$, and added into a $96-$ well plate $(0.1 \mathrm{ml}$ per well) for $24 \mathrm{~h}$, after which the supernatent was removed. The rhTNF- $\alpha$ fusion protein without the GST tag, and the deblocked rhTNF- $\alpha$ fusion protein were each diluted into $1,10,100$ and 1,000 nmol/1 with RPMI-1640 (Gibco-BRL, Invitrogen Life Technologies, Carlsbad, CA, USA). The above dilution, the negative control and the standard TNF- $\alpha$ positive control were added into the wells for another $24 \mathrm{~h}$. MTT $(20 \mu \mathrm{l}, 5 \mathrm{mg} /$ $\mathrm{ml}$ ) was then added to the wells for $4 \mathrm{~h}$ at $37^{\circ} \mathrm{C}$, after which the supernatent was again removed. The crystals were fully dissolved by adding $200 \mu \mathrm{l}$ dimethyl sulfoxide to each well for $0.5 \mathrm{~h}$ at $37^{\circ} \mathrm{C}$. Finally, the absorbance was determined at $570 \mathrm{~nm}$ with a 450 enzyme-labeled meter (GF-M3000; Aloka Medical Equipment Co., Ltd., Tokyo, Japan) and the percentage of dead cells at different concentrations of fusion protein was calculated. The specific activity (activity of TNF- $\alpha$ per mg protein) of the fusion protein and the deblocked protein, based on the definition of an active unit (U) as the concentration which is capable of killing $50 \%$ of cells. .

Establishment of the animal model, and grouping and injection. Frozen S180 cells were recovered and inoculated 
into the abdomens of four healthy mice $(0.1 \mathrm{ml}$ per mouse). The mice were sacrificed by cervical dislocation after seven days and the ascites were extracted under sterile conditions. Ascitic cells were diluted down to $1.8 \times 10^{7} / \mathrm{ml}$ with sterile saline. The cell suspension was injected into 32 Kunming mice $(0.2 / \mathrm{ml}$ per mouse; subcutaneously into the axilla) in order to generate a solid tumor model. The following day, the S180 tumor-bearing mice were randomly divided into four groups after weighing. The groups were: Saline control group (group S); low dose group (group L); middle dose group (group $\mathrm{M}$ ) and high dose group (group H). Saline and saline plus $0.1,0.2$ or $0.3 \mu \mathrm{g} / \mu 1$ of fusion protein $(0.5 \mathrm{ml})$ were administered intraperitoneally every other day for 11 days (i.e. six times in total).

Antitumor effect of the fusion protein and its effect on liver and kidney function. Blood was drawn by removing eyeballs the day following drug withdrawl. The serum of each mouse was preserved at $-20^{\circ} \mathrm{C}$ for measurement of liver function, assessed by levels of alanine transaminase (ALT) and albumin (ALB), and kidney function, assessed by levels of creatinine $(\mathrm{Cr})$ and blood urea nitrogen (BUN). The tumor, liver and kidneys were surgically removed and weighed after measurement of mouse weight, and the liver and kidney indices were calculated: Liver index $(\mathrm{mg} / \mathrm{g})=$ (liver weight/body weight) $x$ 1,000; kidney index $(\mathrm{mg} / \mathrm{g})=($ kidney weight/body weight $) \times 1,000$. The percentage reduction in mean tumor weights between the groups was assessed. The organs were fixed in formalin for analysis.

Determination of $u P A$ in serum. Serum levels of uPA were determined by an enzyme-linked immunosorbent assay (ELISA). ELISA was conducted according to the manufacturer's instructions for uPA. A standard curve was drawn to calculate the concentration of uPA in each group and the reduction rate in each group. The reduction rate of uPA $(\%)=[1-($ mean uPA content of treatment group/mean uPA content of saline control group)] x $100 \%$.

Expression of bcl-2, bax and VEGF by a streptavidin-biotin complex $(s A B C)$ assay. An immunohistochemical method was used to observe levels of expression of bcl-2, bax and VEGF in tumor tissues in mice from each group (6). An immunohistochemical sABC staining method was adopted, and the procedures were followed according to the manufacturer's instructions. Briefly, tissues were fixed by adding neutral formaldehyde-buffered solution into the tissue, prior to routine paraffin imbedding. The slides were dried following $1 \mathrm{~h}$ soak in poly-L-lysine slide anti-creep solution, and tissues were sliced into $4-\mu \mathrm{m}$ slices and routinely de-waxed prior to being incubated in $10 \%$ formaldehyde- $\mathrm{H}_{2} \mathrm{O}_{2}$ for $10 \mathrm{~min}$ at room temperature. The tumor tissue slices were blocked with goat serum confining liquid for $20 \mathrm{~min}$. Rabbit monoclonal anti-bcl-2 (Sigma-Aldrich), anti-bax (Sigma-Aldrich) and anti-VEGF (Santa Cruz Biotechnology, Inc., Dallas, TX, USA) antibodies were incubated overnight at $4{ }^{\circ} \mathrm{C}$ (working concentration, 1:2,000). The secondary antibody (1:2000; biotinylated goat anti-rabbit IgG; Santa Cruz Biotechnology, Inc.) was incubated at $3^{\circ} \mathrm{C}$ for $20 \mathrm{~min}$. $\mathrm{SABC}$ was added (Shanghai Bogu Biological Technology Co., Ltd., Shanghai, China) and incubated at $37^{\circ} \mathrm{C}$ for 20 min prior to $\mathrm{DAB}-\mathrm{H}_{2} \mathrm{O}_{2}$ coloration. Hematoxylin staining was performed. A negative control was established, with PBS replacing the first antibody, in order to rule out non-specific staining. Positive staining of bcl-2, bax and VEGF was yellowish-brown or brown. The positive area was determined from approximately five visual fields in each section at x100 magnification by an MAIS pathological color image analyzer.

Apoptotic cell determination by a TUNEL assay. The TUNEL method was used to observe the percentage of apoptotic cells in tumor tissues of mice from each group (7). Briefly, tissues were sliced and routinely de-waxed. They were then washed in $3 \% \mathrm{H}_{2} \mathrm{O}_{2}$ three times, digested by the protease, dissolved in Tris/ $\mathrm{HCl}, \mathrm{pH} 7.4-8.0$ at $37^{\circ} \mathrm{C}$, and then washed again. Next, $1 \mu 1$ terminal deoxynucleotidyl transferase, $1 \mu 1$ dig-dUTP (Shanghai Bogu Biological Technology Co., Ltd.) and $18 \mu 1$ mark buffer were added and then mixed. The redundant liquid was removed and $20 \mu \mathrm{l}$ mark liquid was added and incubated in a moisture box (Shanghai Yuejin Technology Co., Ltd., Shanghai, China) at $37^{\circ} \mathrm{C}$ for $2 \mathrm{~h}$. The mixture was then washed in PBS three times. The sample was incubated with enzyme labeled anti-fluorescein antibody at $37^{\circ} \mathrm{C}$ for $30 \mathrm{~min}$, and then washed three times again with PBS. DAB coloration was performed for 10-30 min and the sample was then washed with water. Finally the samples were stained with hematoxylin, dehydrated, dehydrated, soaked in dimethylbenzene and mounted. The apoptotic cells were stained yellowish-brown or brown. TUNEL-positive cells were counted on five randomly selected visual fields at $\mathrm{x} 400$ magnification, and the apoptotic index was calculated.

Statistical analysis. The results are presented as the mean \pm the standard error. An analysis of variance test was conducted using SPSS 19.0 (IBM, Armonk, NY, USA) for Windows. $\mathrm{P}<0.05$ and $\mathrm{P}<0.01$ were considered to indicate a statistically significant difference.

\section{Results}

Plasmids contain the foldon, uPA substrate and hTNF- $\alpha$ mutant gene sequences. The two sequencing assays confirmed that a fusion gene sequence with a length of 572 bp was inserted between the two restriction sites of PshA $\downarrow$ and Sac $\downarrow$ in the pET-42a carrier, including the foldon sequence, the uPA substrate sequence and the hTNF- $\alpha$ mutant gene, which was consistent with the intended design.

Urokinase specifically and effectively deblocks the fusion protein. Based on the results of the SDS-PAGE gray scale scan and protein concentration measurement, $2.33 \mathrm{mg}$ target protein without a GST tag was obtained from $1 \mathrm{~g}$ (wet weight) of E.coli. Protein expression was induced by IPTG, and then the protein was purified by GST•Bind ${ }^{\mathrm{TM}}$ before the GST tag was removed by factor Xa. Theoretically, after cleavage by urokinase, the rhTNF protein should change from the original band (of $49 \mathrm{kDa}$ ) to two bands (of $17.5 \mathrm{kDa}$ and $31.5 \mathrm{kDa}$ ). The results of the SDS-PAGE are shown in Fig. 1. By comparing with standard protein controls and the undigested rhTNF protein, two protein bands in the ranges 14.3-20.1 kDa and 
Table I. Tumor inhibition rate of S180 bearing mice.

\begin{tabular}{lcccccc}
\hline Group & $\begin{array}{c}\text { Number } \\
\text { of mice }\end{array}$ & Fatalities & Tumor weight $(\mathrm{g})$ & t-value & P-value & $\begin{array}{c}\text { Reduction in mean } \\
\text { tumor growth }(\%)\end{array}$ \\
\hline $\mathrm{S}$ & 8 & 0 & $0.529 \pm 0.225$ & - & - & - \\
$\mathrm{L}$ & 8 & 1 & $0.289 \pm 0.056$ & 2.737 & 0.016 & 45.37 \\
$\mathrm{M}$ & 8 & 0 & $0.198 \pm 0.078$ & 4.372 & 0.002 & 62.57 \\
$\mathrm{H}$ & 8 & 0 & $0.129 \pm 0.029$ & 4.967 & $<0.001$ & 75.61 \\
\hline
\end{tabular}

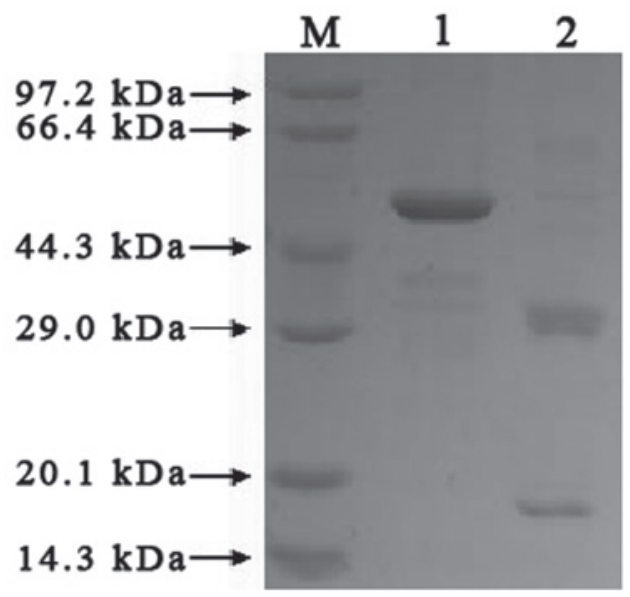

Figure 1. Analysis of the fusion protein by uPA enzyme digestion. Lane M, low molecular weight markers; lane 1 , rhTNF protein; lane 2 , the products of rhTNF protein digested by uPA enzyme digestion. rhTNF, recombinant human tumor necrosis factor; uPA, urokinase-type plasminogen activator.

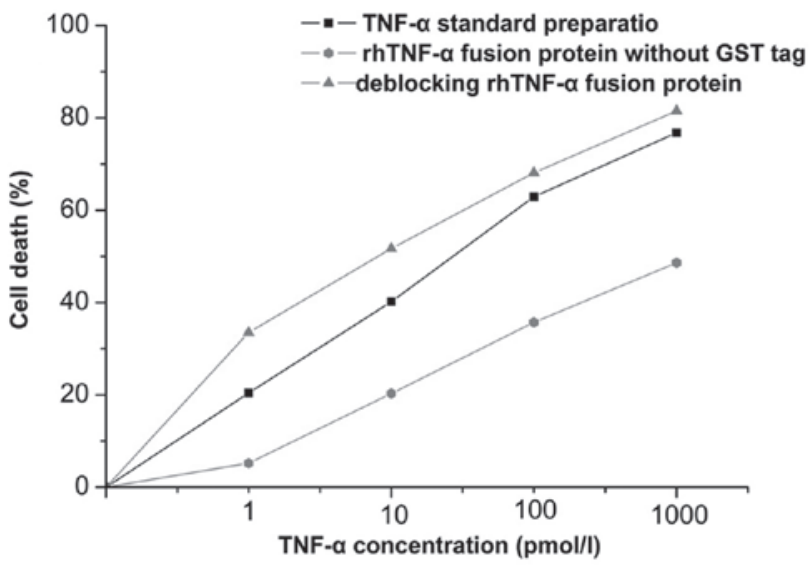

Figure 2. Cytotoxicity of the different treatments on L929 cells. TNF- $\alpha$, tumor necrosis factor- $\alpha$; rhTNF- $\alpha$, recombinant human TNF- $\alpha$.

29.0-44.3 kDa were observed. Given the predicted molecular weight of the cleaved protein, the results suggest that urokinase had an effective and specific deblocking effect on the fusion protein.

Cytotoxic activity of the deblocked fusion protein is significantly higher than that of the fusion protein. In order to examine the effects of the deblocked fusion protein, the cytotoxic activity of tumor cells of the fusion protein and active

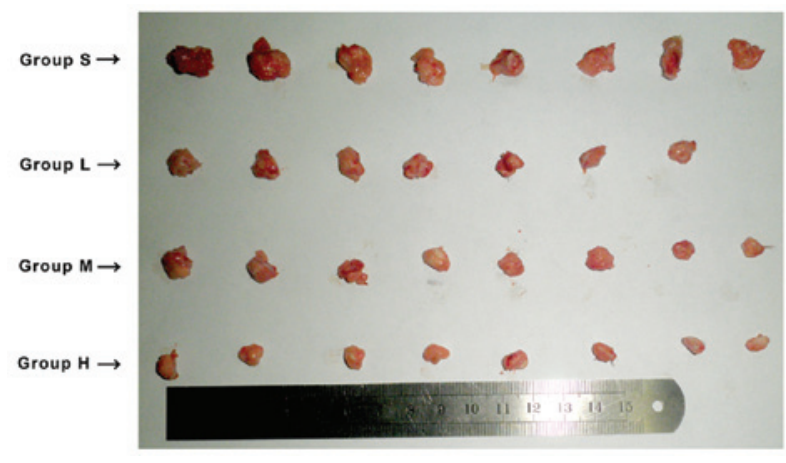

Figure 3. Relative size of the tumors (with $\mathrm{cm}$ ruler for comparison).

fusion protein were detected by L929 cells. As shown in Fig. 2, after $24 \mathrm{~h}$ incubation there was an effect on cell apoptosis, which increased in a dose-dependent manner with the level of the deblocked fusion protein. By contrast, the fusion protein showed no significant cytotoxic activity on L929 cells, as the receptor binding site had been blocked. Based on the regression equation with the concentration values (expressed logarithmically) as the independent variable and the percentage of cell death as the dependent variable, and taking a cytotoxic activity of $50 \%$ as an active unit (U), the specific activity of the fusion protein was calculated as $1.82 \times 10^{5} \mathrm{U} / \mathrm{mg}$, and that of the deblocked fusion protein as $6.30 \times 10^{5} \mathrm{IU} / \mathrm{mg}$.

Injection of the fusion protein into the abdominal cavity reduces tumor size in a dose-dependent manner. S180 mouse cells were selected to generate solid tumor models, as they are an established tumor model $(8,9)$. In the saline control group, tumors growth was first observed four days after being vaccinated with the $\mathrm{S} 180$ cells. By contrast, growth in the high dose group was delayed until the seventh day and thereafter grew more slowly. One mouse in the low dose group died, and the autopsy showed this was most likely to have been due to infection. Tumors from mice in the control group were notably larger than those from mice in the groups treated with the fusion protein. The control group tumors were also harder to extract and showed evidence of infiltrative growth. By contrast, tumors in the fusion protein groups were easier to remove and solitary. The size and weight of solid tumors from each group are shown in Fig. 3 and Table I. The study showed that the fusion protein inhibited growth of S180 tumors in a mouse model, and that the percentage difference in mean tumor weight increased with increasing 
Table II. uPA content in serum.

\begin{tabular}{lcccc}
\hline Group & uPA content $(\mathrm{ng} / \mathrm{ml})$ & t-value & P-value & Reduction rate $(\%)$ \\
\hline $\mathrm{S}$ & $1.466 \pm 0.134$ & - & - & - \\
$\mathrm{L}$ & $1.324 \pm 0.175$ & 1.701 & 0.043 & 9.69 \\
$\mathrm{M}$ & $1.225 \pm 0.137$ & 3.516 & 0.003 & 16.44 \\
$\mathrm{H}$ & $1.035 \pm 0.062$ & 8.173 & $<0.001$ & 29.40 \\
\hline
\end{tabular}

uPA, urokinase-type plasminogen activator.

Table III. Effects of fusion protein on the liver and kidney.

\begin{tabular}{|c|c|c|c|c|c|c|}
\hline Group & Liver index $(\%)$ & Kidney index (\%) & $\operatorname{ALT}(\mathrm{U} / \mathrm{l})$ & $\operatorname{ALB}(g / 1)$ & BUN (mmol/l) & $\mathrm{Cr}$ (umol/l) \\
\hline S & $6.516 \pm 0.867$ & $1.580 \pm 0.286$ & $54.290 \pm 9.268$ & $11.586 \pm 1.753$ & $7.099 \pm 1.710$ & $13.000 \pm 2.944$ \\
\hline $\mathrm{L}$ & $6.383 \pm 0.915$ & $1.501 \pm 0.155$ & $48.710 \pm 9.759^{a}$ & $13.886 \pm 1.617^{\mathrm{a}}$ & $7.096 \pm 0.531$ & $15.57 \pm 1.988$ \\
\hline M & $6.430 \pm 1.208$ & $1.484 \pm 0.253$ & $46.83 \pm 8.208^{\mathrm{a}}$ & $14.533 \pm 1.136^{\mathrm{b}}$ & $7.300 \pm 0.933$ & $15.17 \pm 3.312$ \\
\hline $\mathrm{H}$ & $6.369 \pm 0.700$ & $1.506 \pm 0.126$ & $34.71 \pm 6.370^{b}$ & $14.657 \pm 1.693^{\mathrm{b}}$ & $9.583 \pm 1.457^{\mathrm{a}}$ & $18.29 \pm 3.352^{\mathrm{b}}$ \\
\hline
\end{tabular}

${ }^{\mathrm{a}} \mathrm{P}<0.05$ and ${ }^{\mathrm{b}} \mathrm{P}<0.01$, compared with group $\mathrm{S}$. ALT, alanine transaminase; ALB, albumin; BUN, blood urea nitrogen; Cr, creatinine.
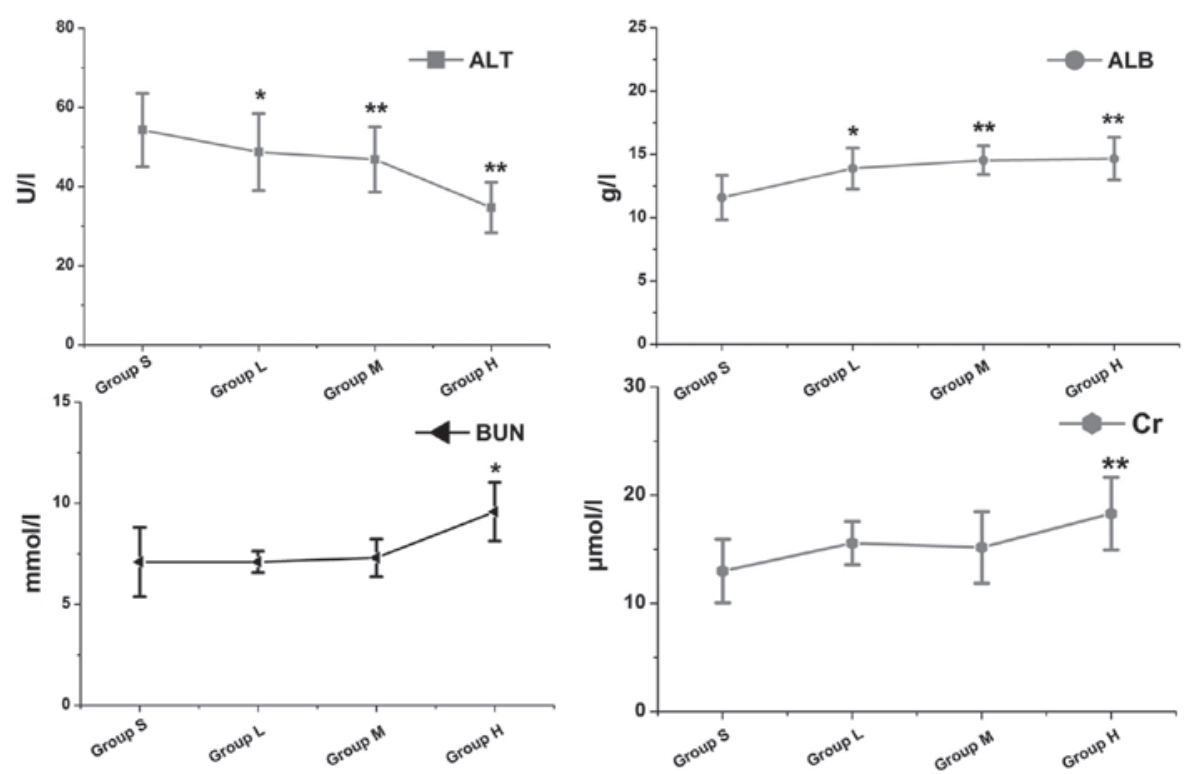

Figure 4. Effects of fusion protein on the liver and kidney. Data are expressed as the mean \pm standard error. ${ }^{*} \mathrm{P}<0.05$ and ${ }^{* *} \mathrm{P}<0.01$, compared with group $\mathrm{S}$. ALT, alanine transaminase; ALB, albumin; BUN, blood urea nitrogen; $\mathrm{Cr}$, creatinine.

doses of fusion protein compared with the control group, rising to $75.61 \%$ in the high dose group.

Levels of serum uPA decrease following fusion protein treatment in a dose-dependent manner. With standard concentration on the vertical axis and optical density on the horizontal axis on logarithmic graph paper, a standard curve was plotted and the serum uPA of each group was calculated. In the high-dose group, the serum uPA level was $1.035 \pm 0.062 \mathrm{ng} / \mathrm{ml}$, which was reduced by $29.40 \%$ compared with the saline control group. uPA levels decreased with increasing doses of the fusion protein. All results were statistically significant $(\mathrm{P}<0.05)$, as listed in Table II.

Fusion protein exhibits a protective effect on the liver at all doses, and a mildly toxic effect on the kidney at higher doses. Liver and kidney indices were calculated based on liver, kidney and body weights. As shown in Table III and Fig. 4, compared with group S, the liver and kidneys indices of tumor-bearing mice in each fusion protein group were not significantly different $(\mathrm{P}>0.05)$. However, levels of ALT and ALB in the fusion protein groups were significantly different 
Table IV. Expression of bcl-2, bax and VEGF in tumor tissue.

\begin{tabular}{lccc}
\hline Group & bcl-2 & bax & VEGF \\
\hline S & $1021.21 \pm 14.32$ & $885.52 \pm 10.23$ & $1160.01 \pm 18.26$ \\
L & $903.33 \pm 9.59^{\mathrm{a}}$ & $921.26 \pm 2.65$ & $1010.55 \pm 11.25^{\mathrm{a}}$ \\
$\mathrm{M}$ & $519.59 \pm 6.47^{\mathrm{a}}$ & $890.49 \pm 9.26$ & $905.38 \pm 5.36^{\mathrm{a}}$ \\
$\mathrm{H}$ & $327.01 \pm 11.36^{\mathrm{b}}$ & $903.24 \pm 6.24$ & $556.74 \pm 10.58^{\mathrm{b}}$ \\
\hline
\end{tabular}

Positive scores were scanned by MAIS pathological color image analyzer. ${ }^{\mathrm{a}} \mathrm{P}<0.05$ and ${ }^{\mathrm{b}} \mathrm{P}<0.01$, compared with group $\mathrm{S}$. VEGF, vascular endothelial growth factor.

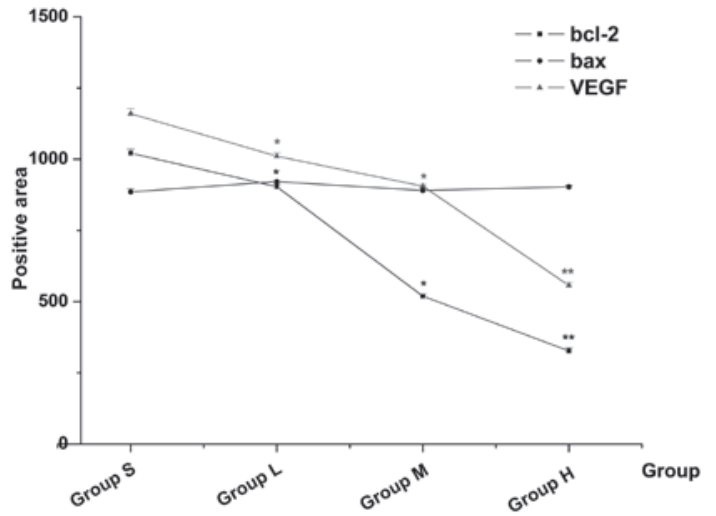

Figure 5. Expression of bcl-2, bax and VEGF in tumor tissues of each group. Data are expressed as the mean \pm standard error. ${ }^{*} \mathrm{P}<0.05$ and ${ }^{* *} \mathrm{P}<0.01$, compared with group $\mathrm{S}$. VEGF, vascular endothelial growth factor.

compared with the control group $(\mathrm{P}<0.05)$. ALT decreased, whilst ALB increased as the dose of fusion protein increased. Levels of BUN and Cr levels in groups $\mathrm{L}$ and $\mathrm{M}$ were not significantly different from that in group S. However, BUN and $\mathrm{Cr}$ were significantly higher in group $\mathrm{H}(9.583 \pm 1.457$ and $18.29 \pm 3.352 \mathrm{mmol} / \mathrm{l}$, respectively) compared with that in the control group $(7.099 \pm 1.710$ and $13.000 \pm 2.944 \mathrm{mmol} / \mathrm{l}$, respectively).

Immunohistochemical results of bcl-2, bax and VEGF expression. The results of the immunohistochemistry are shown in Table IV and Figs. 5 and 6. The expression of bcl-2 and VEGF in the fusion protein groups decreased as the dose increased (all $\mathrm{P}<0.05$ ). The positive areas of bcl-2 and VEGF expression in group $\mathrm{H}$ were $327.01 \pm 11.36$ and $556.74 \pm 10.58$, respectively. These were significantly lower than that in group $\mathrm{S}(\mathrm{P}<0.01)$. Notably, the expression of bax was not significantly different compared with that in group $\mathrm{S}$ $(\mathrm{P}>0.05)$.

Apoptosis is increased by fusion protein treatment compared with control. The apoptotic nuclei in tumor cells from each group were detected by the TUNEL assay (Fig. 7), as described previously (10). The apoptotic index of group $\mathrm{S}$ was $4.50 \pm 1.05 \%$. Those of groups $\mathrm{L}$ and $\mathrm{H}$, were $34.01 \pm 5.20$ and $71.16 \pm 3.44 \%$ respectively, and were significantly higher than in group $\mathrm{S}(\mathrm{P}<0.01)$. The apoptotic index of group $\mathrm{M}$ was $24.46 \pm 4.34 \%$, which was also significantly different compared with group $\mathrm{S}(\mathrm{P}<0.05)$. Although the apoptotic index was lower in group $\mathrm{M}$ than in group $\mathrm{L}$, there was a general dose-dependent increase in apoptosis following fusion protein treatment (Fig. 8).

\section{Discussion}

With increasing understanding of the molecular biology of cancer in recent years, targeted therapy has become an increasingly important part of cancer therapy, where significant progress has been made in the treatment of various types of tumors (11-12). To date, research on hTNF- $\alpha$ structural transformation, has suggested that using molecular methods to transform TNF- $\alpha$ molecular structure may be of great significance in the development of cancer therapies (13-14). A novel tumor-targeting transformation strategy involving hTNF- $\alpha$ was adopted in this study. Within each hTNF- $\alpha$ monomer, the eight amino-acid residues at the $\mathrm{N}$-terminal are replaced by a urokinase substrate sequence, which is coupled with foldon domain sequences from bacteriophage T4 fibritin at the $\mathrm{N}$-terminal. Theoretically, the foldon sequence is used to block the N-terminal at the bottom of the molecular structure of hTNF- $\alpha$, and the blocked N-terminal is able to autonomously form trimers, following those formed by whole hTNF- $\alpha$. As a result, the enzyme substrate sequence is involved in deblocking the receptor binding site for hTNF- $\alpha$. That is, the blocked fusion protein does not exhibit the normal activity of hTNF- $\alpha$. However, when recombinant hTNF- $\alpha$ reaches the tumor site, where uPA is highly expressed, this enzyme will cleave the enzyme substrate sequence, thus cutting off the triple helix foldon structure along with parts of the uPA substrate sequence. The receptor binding site is then exposed, resulting in activated hTNF- $\alpha$, which is then involved in mediating tumor cell apoptosis.

A recombinant plasmid containing hTNF- $\alpha$, uPA and foldon sequences, which was transformed into Rosetta2 (DE3) under specified conditions was produced. The plasmid was induced to express soluble fusion protein by Kana and Cam, which was then purified by (GST) resin purification kit. The pick-up rate of fusion protein was $0.23 \%$ and the purification rate was $93 \%$. Additionally, the analysis of fusion protein digestion by uPA showed that urokinase had an efficient and specific deblocking effect on this fusion protein. Through the analysis on the cytotoxic activity of the fusion protein, it was observed that the deblocked rhTNF- $\alpha$ fusion protein significantly increased cell death compared with the inactive fusion protein. Moreover, the percentage of L929 cell death was positively correlated with 

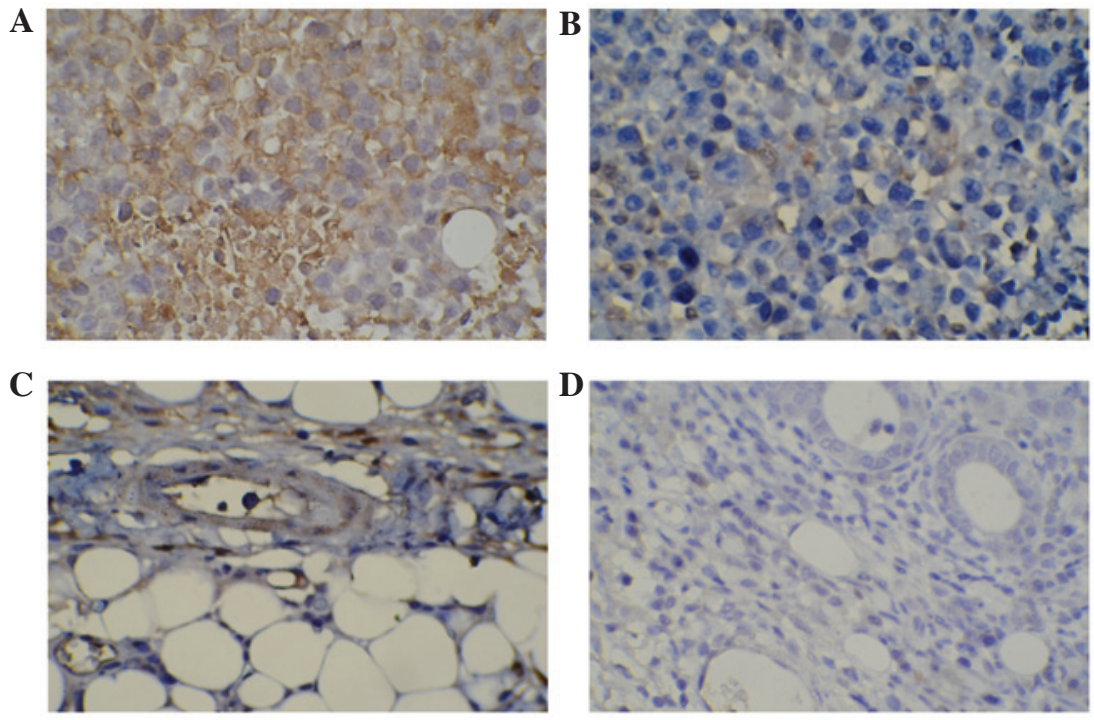

Figure 6. Results of immunohistochemistry. Positive signals of the immunohistochemistry in the cytoplasm, marked by presence of yellowish-brown or brown fine granules. (A) bcl-2 positive cells of group S; (B) bcl-2 positive cells of group $\mathrm{H}$; (C) VEGF positive cells of group S; (D) VEGF positive cells of group H. VEGF, vascular endothelial growth factor. Magnification, $\mathrm{x} 400$; blue staining indicates the nuclei of the cells.
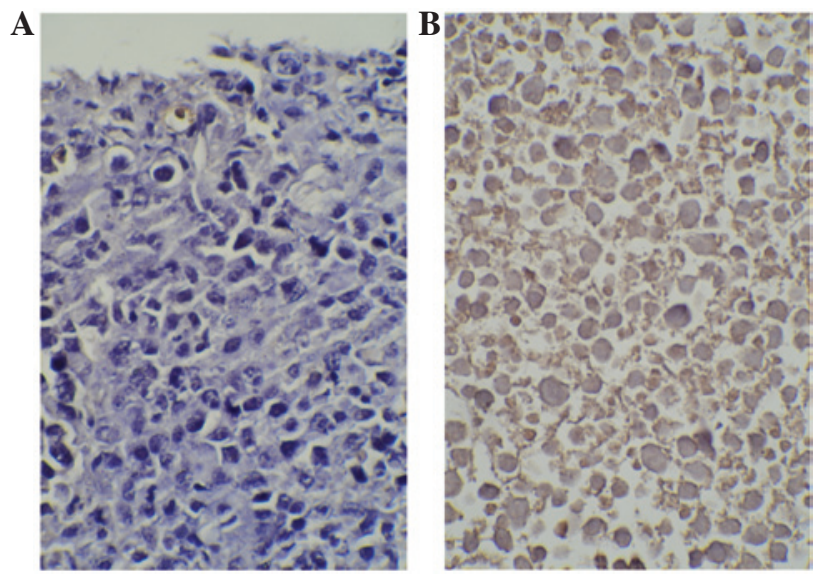

Figure 7. Tumor cell apoptosis. The normal nuclei of tumor cells were clearer and more concentrated, and stained blue or blue-purple. Apoptotic cells appear brownish-yellow or brown and full of cytoplasm. (A) tumor cell apoptosis in group S; (B) tumor cell apoptosis in group $\mathrm{H}$. Magnification, $\mathrm{x} 400$; blue staining indicates the nuclei of the cells.

the level of the deblocked protein, while the fusion protein had no significant biological activity. This was consistent with the theory of transformation. The specific activities of rhTNF- $\alpha$ and deblocked fusion protein were measured. They were $1.82 \times 10^{5}$ and $6.30 \times 10^{5} \mathrm{IU} / \mathrm{mg}$ respectively. These values are markedly higher than those reported by Jia et al (15).

The results also showed that the inhibitory effect of the fusion protein on tumor growth was dose-dependent $\left(\mathrm{r}^{2}=0.993\right)$ in S180 tumor-bearing mice, and that the percentage reduction in mean tumor volume in the high dose group was up to $75.61 \%$ compared with the control group. uPA is the main plasminogen activator in vivo that cleaves plasminogen to plasmin. Plasmin hydrolyzes various components of the extracellular matrix to promote tumor cell invasion into adjacent tissue as well as metastasis. Furthermore, the level of uPA in serum is positively correlated with the extent of metastatic spread and activity of tumors (16). The current study showed that the level

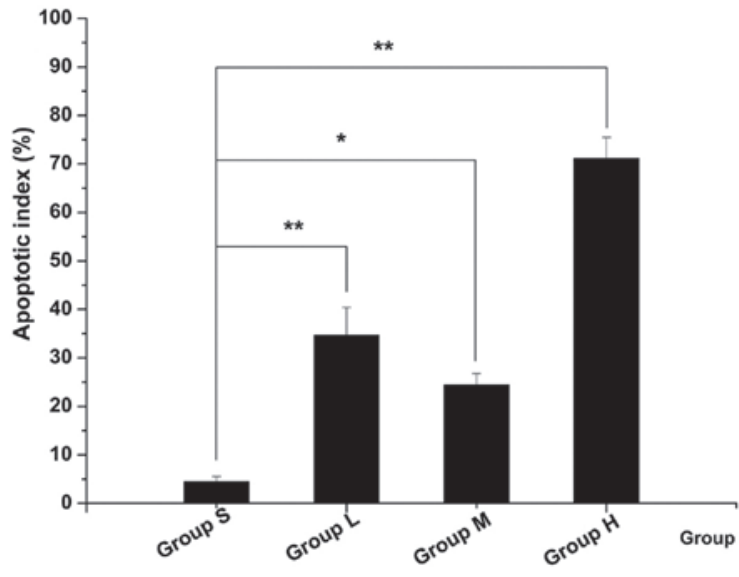

Figure 8. Comparison of tumor cell apoptosis in different groups. Data are expressed as the mean \pm standard error. ${ }^{*} \mathrm{P}<0.05$ and ${ }^{* *} \mathrm{P}<0.01$, compared with group $\mathrm{S}$.

of uPA in tumor-bearing mouse serum decreased as the dose of fusion protein increased. Furthermore, the levels of uPA in the high dose group decreased by $29.40 \%$, and tumors were better circumscribed and easier to remove than those in the control group. The changes in levels of uPA further reflect the anti-tumor effects of the fusion protein. The results demonstrated that the fusion protein induced a greater degree of tumor cell apoptosis and that the nuclei in these cells typically showed pyknosis and lysis. These observations were most evident in the high-dose group, in which the percentage of apoptotic cells was increased to $71.16 \%$. Furthermore, studies on apoptosis show that bcl-2 and bax are the most important inhibitor and promotor of apoptosis in the Bcl-2 family, respectively (17). Upregulation of bcl-2 or downregulation of bax can inhibit apoptosis in a variety of types of tumor. Conversely, downregulation of bcl-2 or upregulation of bax can promote apoptosis in a number of types of tumor. The expression of bcl-2 in tumor tissues detected by immunohistochemistry decreased 
as the dose of the fusion protein increased, whilst the dose of the fusion protein had little effect on the expression of bax.

VEGF is a type of highly specific cytokine, which promotes angiogenesis and increases vascular permeability It is also closely associated with tumor growth and metastasis (18). The expression of VEGF in different types of tumor tissues, detected by immunohistochemistry, showed that VEGF-positive areas and the dose of rhTNF were negatively correlated. Gu et al (19) demonstrated that TNF- $\alpha$ selectively inhibited tumor vascular endothelial cells and downregulated the expression of the VEGF receptor to inhibit angiogenesis. Whether this fusion protein may also reduce the expression of the VEGF receptor requires further investigation.

TNF- $\alpha$ is frequently investigated as a potential therapy in cancer research, but its antitumor mechanism remains unclear. The fusion protein produced in this study had significant antitumor effects in S180 tumor-bearing mice. A number of mechanisms may be involved. Firstly, the fusion protein inhibited the expression of uPA in tumor tissue (or accelerates its hydrolysis) reducing the capacity of the tumor to invade and transform. This led to a reduction in tumor growth. Secondly, the fusion protein reduced the expression of bcl-2, which promotes tumor cell apoptosis and inhibits tumor growth. Thirdly, the fusion protein acts on vascular endothelial cells of the tumor tissue to inhibit the expression of VEGF, thus exhibiting anti-angiogenic activity.

In order to explore the effects on liver and kidney function of the tumor-bearing mice, a series of indicators were examined, which showed that the fusion protein had no significant effect on liver and kidney indices. The decreasing level of ALT and increasing level of ALB suggests that the fusion protein was able to reduce tumor-induced compensatory liver injury, and enhance the synthetic function of the liver. In terms of kidney function, the levels of BUN and $\mathrm{Cr}$ in tumor-bearing mouse serum varied little in the low dose and middle dose groups compared with the control group, which indicated that the fusion protein had no significant effects on mouse kidney function at these doses. However, BUN and $\mathrm{Cr}$ did increase marginally in the high dose group, indicating a degree of reversible or irreversible kidney injury at this point. Since the fusion protein may have a protective effect on the liver and appear not to affect kidney function within a certain dose range, the toxic effects of TNF may be ameliorated to a certain extent.

In conclusion, the present study obtained a high pick-up rate of rhTNF- $\alpha$ fusion protein mediated by urokinase through plasmid construction. This protein showed a clear effect on tumor cell growth and apoptosis in S180 tumor-bearing mice, as well as a low toxicity. There is thus significant potential for its use in a range of clinical applications for the treatment of cancer.

\section{Acknowledgements}

This study was supported by the First Science and Technology Program of Guangdong province (grant no. 2008B030301023), the Science and Technology Program of Higher Learning Institutions in Dongguan (grant nos. 200910815264 and 2012108102016) and the Innovative Experiment Program of College Students of Guangdong (grant no. KY1040). Furthermore, the authors would like to thank all the teachers at the Clinical Biochemistry Staff Room Guangdong Medical College Dongguan for their technical assistance.

\section{References}

1. Van Ostade X, Vandenabeele P, Everaerdt B, et al: Human TNF mutants with selective activity on the p55 receptor. Nature 361: 266-269, 1993.

2. Gerstein ES, Shcherbakov AI, Kaz'min AI, et al: Urokinase and tissue plasminogen activators and their type-1 inhibitor (PAI-1) in gastric cancer. Vopr Onkol 49: 165-169, 2003 (In Russian).

3. Morodomi Y, Yano $\mathrm{T}$, Kinoh $\mathrm{H}$, et al: BioKnife, a uPA activity-dependent oncolytic Sendai virus, eliminates pleural spread of malignant mesothelioma via simultaneous stimulation of uPA expression. Mol Ther 20: 769-777, 2012.

4. Thummarati P, Wijitburaphat S, Prasopthum A, et al: High level of urokinase plasminogen activator contributes to cholangiocarcinoma invasion and metastasis. World J Gastroenterol 18: 244-250, 2012.

5. Wang S, Chen T, Chen R, et al: Emodin loaded solid lipid nanoparticles: preparation, characterization and anti-tumor activity studies. Int J Pharm 430: 238-246, 2012.

6. Zhang XJ, Yue J and Zhao TB: Expression change of TNF- $\alpha$ in myocardium and hepatic tissue of rats with compound stress of hyperthermia and lipopolysaccharide. Asian Pac J Trop Med 6: 300-304, 2013.

7. Phalitakul S, Okada M, Hara Y, et al: Vaspin prevents methylglyoxal-induced apoptosis in human vascular endothelial cells by inhibiting reactive oxygen species generation. Acta Physiol (Oxf) 209: 212-219, 2013.

8. Han W, Wang S, Liang R, et al: Non-ionic surfactant vesicles simultaneously enhance antitumor activity and reduce the toxicity of cantharidin. Int J Nanomedicine 8: 2187-2196, 2013.

9. Jiang $\mathrm{Y}$, Jiang $\mathrm{X}$, Law $\mathrm{K}$, et al: Enhanced anti-tumor effect of 9-nitro-camptothecin complexed by hydroxypropyl- $\beta$-cyclodextrin and safety evaluation. Int $\mathrm{J}$ Pharm 415: 252-258, 2011.

10. Zhou S, Yang Y, Yang Y, et al: Combination therapy of VEGF-trap and gemcitabine results in improved anti-tumor efficacy in a mouse lung cancer model. PLoS One 8: e68589, 2013.

11. Weber WA, Czernin J, Phelps ME and Herschman HR: Technology Insight: novel imaging of molecular targets is an emerging area crucial to the development of targeted drugs. Nat Clin Pract Oncol 5: 44-54, 2008.

12. Klener P Jr and Klener P: Molecularly-targeted and biological anti-cancer therapy. Folia Biol (Praha) 58: 1-6, 2012.

13. McGuire AT and Mangroo D: Cex1p is a novel cytoplasmic component of the Saccharomyces cerevisiae nuclear tRNA export machinery. EMBO J 26: 288-300, 2007.

14. Zhao Q, Hou G, Huang D and Chen S: Construction and expression of hTNF-alpha fusion protein mediated by MMP1. Sheng WuYi Xue Gong Cheng Xue Za Zhi 28: 534-537, 2011 (In Chinese).

15. Jia FL and Khan A: Studies on acute toxicity and serum level changes of tumor necrosis factor. Zhongguo Yi Xue Ke Xue Yuan Xue Buo 11: 302-305, 1989 (In Chinese).

16. Horn LC, Pippig S, Raptis G, et al: Clinical relevance of urokinase type plasminogen activator and its inhibitor type 1 (PAI-1) in squamous cell carainoma of the uterine cervix. Aust N Z J Obstet Gynaecol 42: 383-386, 2002.

17. Strasser A, Cory S, Adams JM: Deciphering the rules of programmed cell death to improve therapy of cancer and other diseases. EMBO J 30: 3667-3683, 2011.

18. Sivaprasad S, Govardhan B, Harithakrishna R, et al: Association of vascular endothelial growth factor (VEGF) gene polymorphism and increased serum VEGF concentration with pancreatic adenocarcinoma. Pancreatology 13: 267-272, 2013.

19. Gu CP and Zhang YP: Progress on anti-tumor mechanism of tumor necrosis factor-alpha. Bulletin of Chinese Cancer 16: 102-105, 2007 (In Chinese). 